\title{
CarSaaf - A Case Study from Karachi
}

\author{
Aamir Saeed*
}

\begin{abstract}
CarSaaf is an entrepreneurial venture in Karachi that can be called a Blue Ocean venture on the basis of Create and not compete, that is the true spirit of Blue Ocean Strategy. It differentiated itself with the low cost and created a new market avoiding competing with the run of a mill car wash ventures in Karachi. The value proposition of CarSaaf in comparison to typical car wash ventures is compared through the tool of Buyer Utility Map. The Buyer Utility map is used to study the car wash sector in Karachi, and to identify the consumer pain points of a particular sector. This case, therefore, tends to identify the pain points of consumers in the typical car wash sector of Pakistan, that are addressed by the CarSaaf to introduce a new venture based on providing the solutions through addressing the pain points and to understand the differentiation strategy of CarSaaf, through Buyer Utility Map tool. Utilizing the Buyer Utility Map tool eight pain points of consumers were identified in the car wash industry, that were addressed by CarSaaf for V alue Innovation.
\end{abstract}

Keywords: CarSaaf, Entrepreneurial venture, Blue Ocean, Karachi.

JEL Classification: ZOO

\section{INTRODUCTION}

Karachi according to its population is the eleventh largest city in the world (Ali \& Shams 2020). It has been estimated in the year 2014 that there are 3.6 million registered vehicles on the roads of Karachi city which includes 450,000 commercial vehicles and 1.25 million cars (Chen et al., 2020). However, the estimated data is seven years old and it is expected that it would have been increased by the launch of Uber and Careem. The popularity of hailing rides is not only specific to cars, but recently other types of vehicles having the capacity of more than ten passengers are also in use by the ventures like Airlift and Swvl.

The car wash industry is stratified into organized and unorganized sectors. The organized car wash sector is registered, carried operations as per the instructions of legal authorities and is usually owned by the franchises of Patrol pumps like Pakistan State Oil, Shell, or Caltex. However, the majority of car washing stations are unorganized and lack professional standards. They carried out their operations with poor and ill-maintained infrastructure. The wash time for a car is generally 40 minutes as per standards excluding the waiting time. This average time can be longer on special occasions. Besides the special occasions, the average time is also longer on weekends and national holidays. People in the car often demand car wash due to poor road conditions and high pollution (Ghaly et al., 2021). Due to high pollution that usually is the result of dust, smoke emitting vehicles, and poor rainfall the need for a car wash is frequent as compared to other cities.

In comparison to the need for frequent car wash service, the car wash stations are limited in

*Associate Professor, Marketing Department, Institute of Business Management, Karachi, Pakistan. Email:aamir.saeed@iobm.edu.pk (Corresponding Author) 
number. Most of them are outdated in contrast to modern car wash stations, where the car wash is carried out through a conveyer belt, which one can find very common in developed countries. Besides being outdated and limited in numbers, the car wash stations also have poor infrastructure, outdated equipment, bad customer service, and non-professional employees. This leads to opportunities for new entrants and increased customer fatigue.

Research also indicates that car wash customers often delay or postpone the service of car wash due to longer washing time (Dholakia et al., 2010). This however is not only specific to waiting time but the high cost of service, lack of appropriate washing equipment, unprofessional car washing team, water wastage, environment, and distance of car wash facility, consumers usually delay or postpone their purchase of service. These unfavorable factors have resulted in mushroom growth of tens of unskillful and nonprofessional street car cleaners. These unskilled cleaners are available in every street who just wipe the dirt and use soaked cloth for cleaning the car. They charge around 500 to 1000 monthly depending on the size of the car, residential area and the car make. Their services cannot be compared with the professional car wash. Though, such services can be preferred due to cost constraints and time.

\section{BUYER UTILITY MAP FOR CAR WASH SECTOR IN KARACHI}

The pain points of car wash consumers based on their interviews, observations and involvement of customers indicated in the buyer utility map are as follows (Serial numbers are references in the table of Buyer Utility Map):

\section{Customer Productivity and Purchase}

There is a lack of a proper mechanism of ordering and delivery of services in the car wash industry. It lacks the availability of ordering options that can save time and reduce the fatigue of consumers. The only option available to the car was for consumers is to personally visit the car wash service station and wait for their turn. This makes the car wash industry extremely unattractive for consumers as it increases fatigue and makes this sector unwelcoming to women.

\section{Customer Productivity and Use}

During availing the services of the car wash, usually, there is no proper arrangement where a customer can sit and wait. Usually, the customer waits in a very unhygienic, and hot environment exposed to humidity and sun.

\section{Customer Productivity and Supplements}

Supplements required to carry the car wash are usually hosed pipes. However, there is a number of other equipment required to get the work done professionally. Customers are also interested in getting the air filter cleaned, tires, and oil checked. To carry out these functions the service stations usually lack the equipment or lack skills. 
The Six Stages of the Buyer Experience Cycle

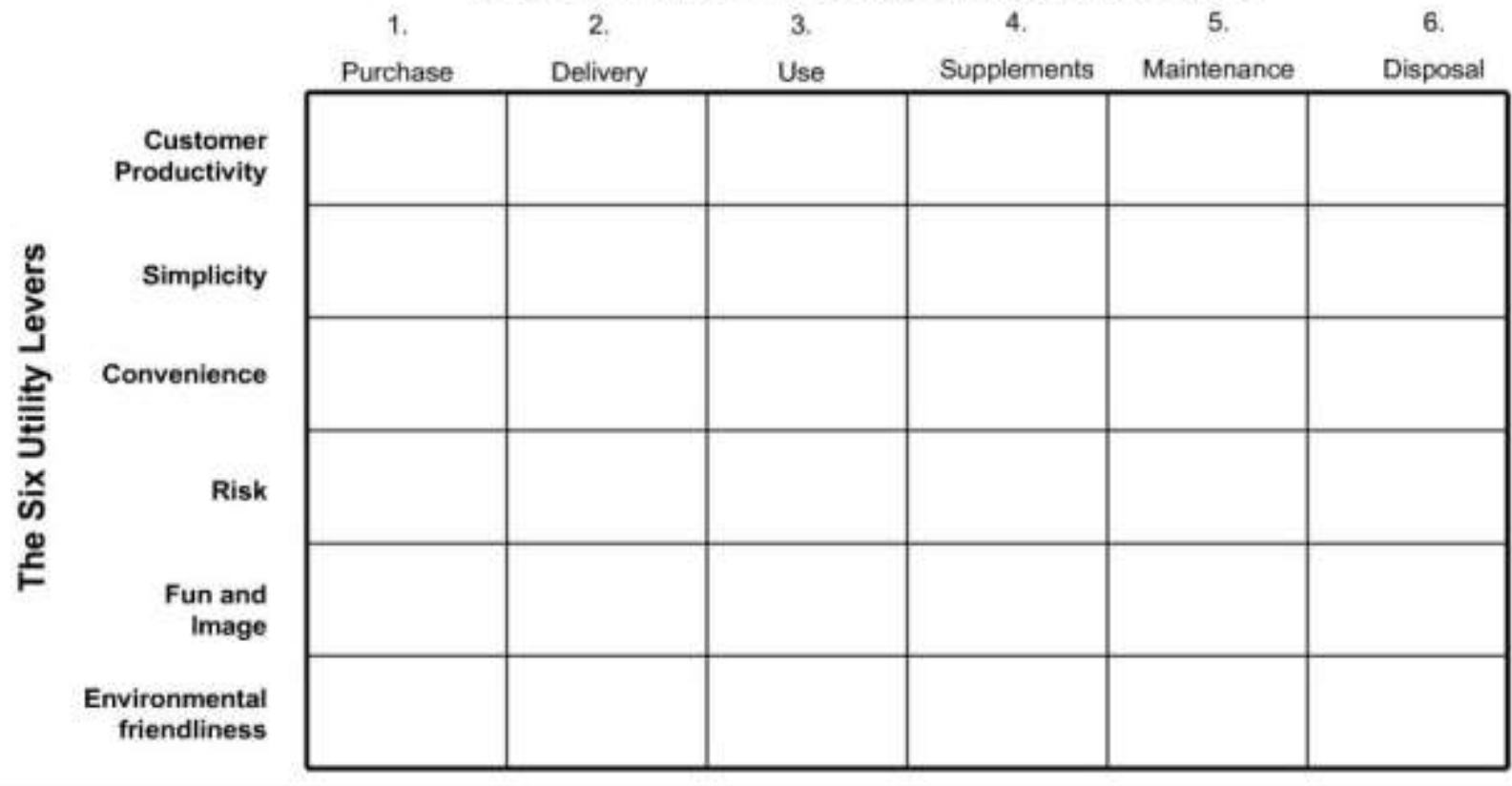

Figure 1: Buyer Utility Map

\section{Customer Productivity and Disposal}

To dispose of dust, dirt usually the car wash service stations use high air pressure instead of vacuum cleaners. This makes the environment dusty and the dust gets in the car again. This creates discomfort for the customer and causes suffocation to the customers who want to monitor the service themselves.

\section{Risk and Purchase}

The water and oil used in cleaning and non-availability of the drying process increase the risk of rusting and body erosion of a vehicle. Wet cars especially engine catch dust immediately after wash.

\section{Risk and Delivery}

The risk in service delivery vehicle erosion, shortening the life of plugs, point, battery and battery generator especially of a smaller vehicle. This results in a problem of a car starting ignition issues.

\section{Fun and Image and Purchase}

There is no fun in the purchase, delivery, and use of car wash services. In Karachi, it is an extremely boring and time-consuming activity. During the wait for his turn, customers sit in an unhygienic environment, usually, there is nothing to do during that time. And most of the facilities lack a waiting area.

\section{Environmental friendliness and Use}

The car wash sector is the least environmentally friendly in Pakistan. A lot of water is wasted during the process (Zaneti et al., 2013). In a city where there is already water scarcity, people discourage water wastage (Tabassum et al., 2020). Usually, the used water is not properly disposed of and go to sewerage lines, and roads. There is no practice of recycling water, however, according to one survey; people are ready to pay a little more for this innovation. 


\section{SERVICES OF CARSAAF}

CarSaaf is a business venture that tried to fill the gap. Starting with limited resources by friends in Karachi, CarSaaf is an effort to serve car wash customers in a better and more professional way. Rather than waiting for a long time in a queue in the unhygienic and dirty condition in hot weather CarSaaf offers car wash services at the doorsteps of customers. Their services are unique in many ways.

\section{Booking and Appointments}

There is no proper mechanism for ordering and delivering in the car wash industry. There are no options for orders that can reduce fatigue and save the time of customers. The only single option available to car wash customers is to personally visit the station and wait for their turn. This makes the car wash industry extremely unattractive for consumers as it increases fatigue and makes this sector unwelcoming to women. CarSaaf tried to fill this gap by offering numerous options to customers in availing of car wash service. One can schedule a time for a car wash via having an appointment through phone, email, or contacting the CarSaaf team through social media.

\section{Making the waiting time productive}

During availing the services of a car wash, usually, there is no proper arrangement where a customer can sit and wait. Usually, the customer waits in a very unhygienic, and hot environment exposed to humidity and sun. As CarSaaf service is provided at the doorstep of consumers or where the customer is interested in avail the service, the waiting in an unhygienic, dirty and humid environment is eliminated. The customer may ask for executing the service when he or she parked the car for dining in or at any parking lot and may have their car washed while shopping or busy in-office meetings.

\section{Updated Equipment}

The main equipment required to carry the car wash is usually hose pipes. However, there is a number of other equipment required to get the work done professionally. CarSaaf uses up-to-date and technically advanced equipment to get the work done. It uses vacuum cleaners, and steam jet technology. The steam jet is technology-enabled to get the wash complete economically. The updated technology also minimizes the unpleasant smell in a car due to wet seats and mats through typical car stations.

\section{Risk}

Typical car wash through stations increases the risk of wear and tear of the car body (SañudoFontaneda et al., 2014). The water and oil used in cleaning and the non-availability of the drying process increase the risk of rusting and car body erosion (Mukaddas et al., 2021). The wet cars especially the engine catch dust immediately after wash. Another common problem is the wetting of plugs of the cars resulting in problems in starting and ignition issues. As the job is carried through steam and vacuum cleaner, therefore, the risk of erosion is minimal. Also, the chance of dust going back into the car is reduced.

\section{Environmental friendliness}

The car wash sector is the least environmentally friendly. In the world including Pakistan and especially in Karachi water is becoming a scarce resource and in the process of a car wash, a lot of water is wasted. There is no mechanism for water recycling. To some consumers, it is highly 
demotivating and discouraging. In contrast to hundreds of liters of water consumed in a single car wash, CarSaaf utilizes five liters of water through steam technology. This is a very important consideration for consumers who are much more concerned about saving water.

Table 1: CarSaaf Services and Rate Card

\begin{tabular}{lllll}
\hline Value Safai: Rs. & Super Safai: Rs. & Full-Service Safai: Rs. & VIP Safai: Rs. & VIP Plus Safai: \\
$\mathbf{8 7 5}$ & $\mathbf{1 4 7 5}$ & $\mathbf{1 7 7 5}$ & $\mathbf{2 0 7 5}$ & $\mathbf{4 5 7 5}$ \\
\hline Steam cleaning & All Options of & All options of Super Safai & All options of & All Options of VIP \\
of: & Value Safai plus & plus Steam cleaning of: & VIP Safai Plus & Safai Plus steam \\
Exterior Body, & Steam Cleaning of: & Seats Vacuum \& Brush, & Steam cleaning & cleaning of: \\
Windows Rims & Value Safai, Mats & Headliner Vacuum \& Brush, of: & Floor cleaning, \\
\& Tyres & Vacuum \& $\quad$ Door Hinges Steam Chassis Steam & Headliner \& \\
& Brushing, Floor & Cleaning, AC Steam Safai & Sanitization \\
& Vacuum \& Brush, Sanitization, Mats Steam & Leather/Rexine \\
& Trunk Vacuum \& & Dryclean, Engine Bay Steam & Seats, Door Panels \\
& Brush, & Safai, Engine Bay Polish, & Sanitization, \\
& Dashboard/Console & Trunk Steam Safai, & Exterior Body \\
& \& Sanitization & Dashboard Polish & Wax Treatment \\
\hline
\end{tabular}
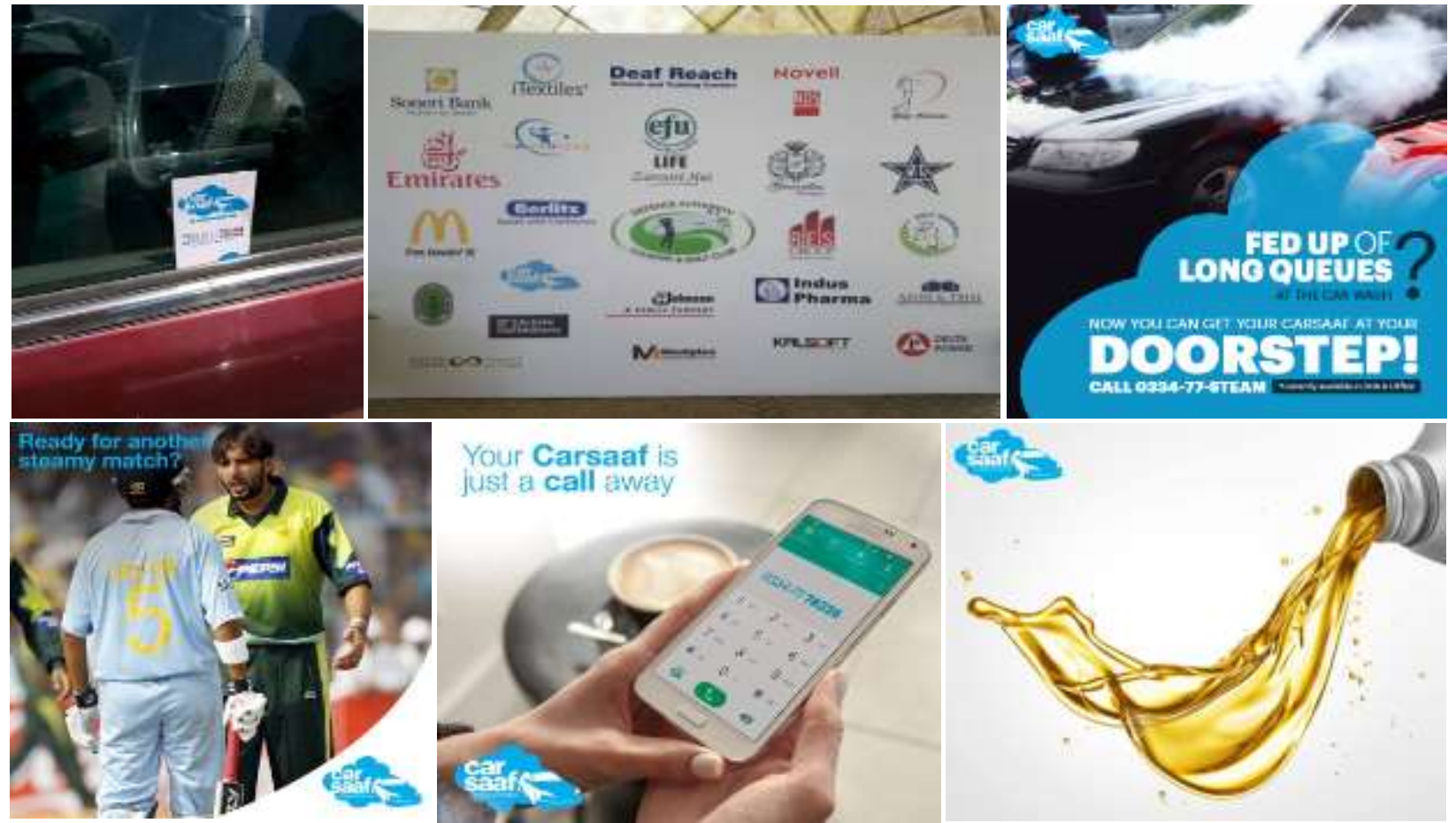

Figure 2: CarSaaf Promotion and Sponsorships 

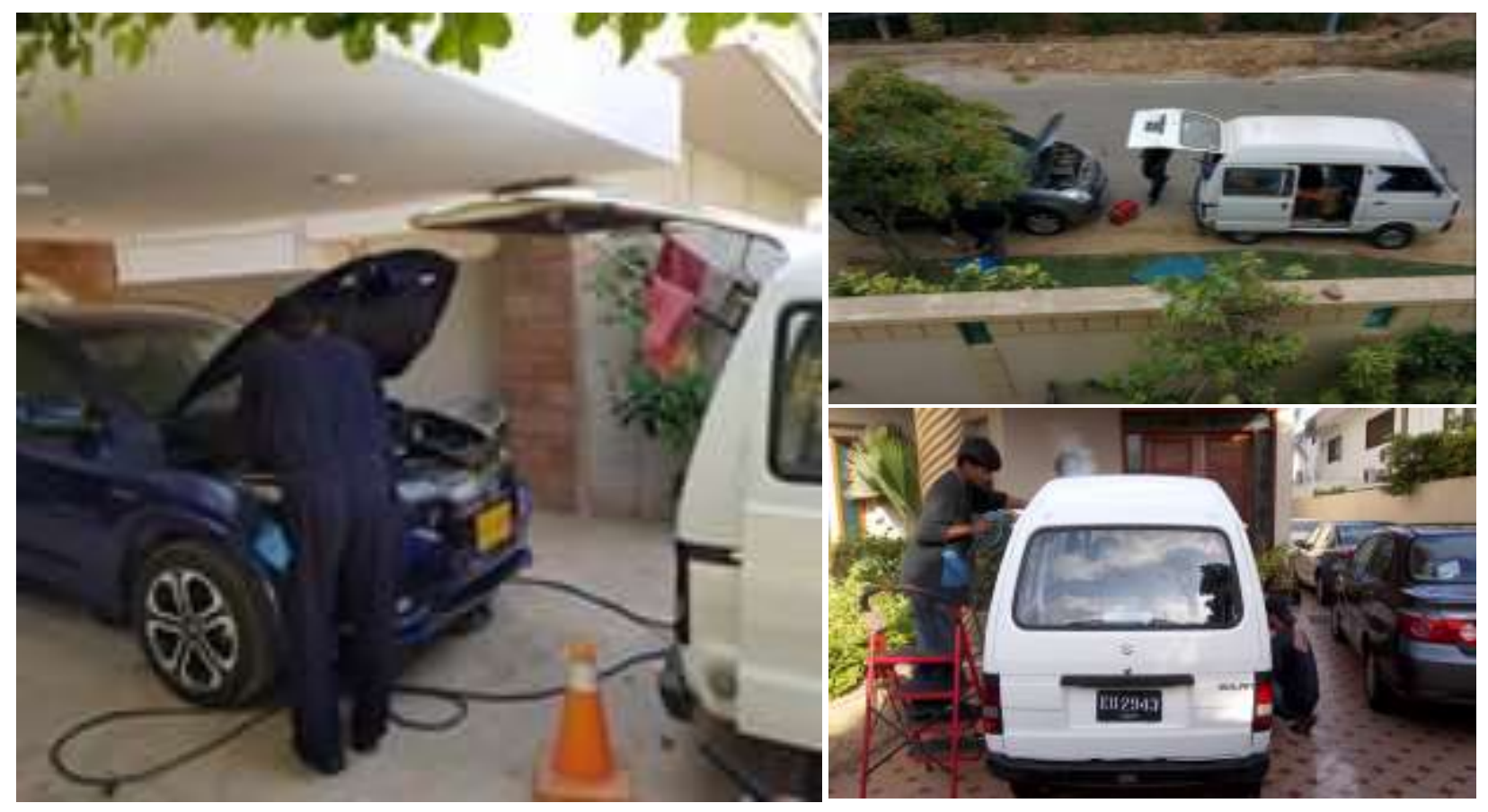

Figure 3: Executing CarSaaf Service at customers' doorsteps

\section{MISCELLANEOUS REVIEWS OF RANDOM CUSTOMERS EXTRACTED FROM CARSAAF FACEBOOK PAGE}

Today I got my car cleaned by CarSaaf at my place really a perfect job was done. They did it by high pressure steam the boys knew there job, it was done very well and in time.

Taha Ahmed reviewed CarSaaf - 5*

25 July - a

Had a great experience, Workers were friendly, they did an amazing job, they were on time. overall great experience Insha Allah will be going to use this service again in the future 
9 August $2017 \cdot 9$

\section{Has service resumed? Any ETA?}

Oldest
O comment

CarSaaf Hello Akbar. Not yet but we will notify you soon as we resume operations $\because$

Like - Reply · $1 y$

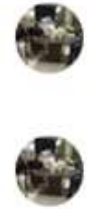

Akbar Khan OK, thank you.

Like - Reply - 1y

Akbar Khan Any updates here? Service still suspended?

Like - Reply - $47 w$

a. CarSaaf Yes sir, we have resumed our services

You can WhatsApp us on $0334-777-8326$ to reserve your CarSaaf $\because$

Like - Reply - $47 \mathrm{w}$

\section{Zohaib Hassan reviewed CarSaaf -}

1 February 2017

Had a worst experience of service with them. First they booked my car @ 2.30 PM than reschedule it to $4.30 \mathrm{PM}$ and after all showed up after 6.00 PM. As it was already maghrib and sunlight was getting dim they started doing work in dark. After they finished the work after 3 hours and just steaming my car with steamer and rubbing it cloth. Next day I found that my roof cloth was damaged, meter of my unused Honda Civic 2013 was full of scratches, roof lighting system was not working and side skirt moldings were damaged and even not working. I called them to kindly visit my car again and come up with some solution for the damaged they have done and guess what they did. They denied all the damage they did to my car and rather than a simple excuse started arguing. CarSaaf team we call you guys to make our loved cars look good not for you cheap guys collecting heavy service money for just steaming the cars. Will never recommend anyone to use your pathetic service. 


\section{CarSaaf Mr. Zohaib,}

Firstly, your appointment was booked on the 25th of January for Saturday, for the 28th of January at 2:30PM. The very next day on the 26th, we asked if we could make it 4:30 instead of $2: 30$ and you agreed. As we do with all our clients, we called you to notify you well in advance that we will be arriving an hour late because of heavy traffic. We reached your doorstep between $5: 30$ and $5: 45$. We gave 3-4 hours of attention to your car whilst our site manager and yourself supervised the team.

After we completed your car, we asked you to check it thoroughly in case you were not satisifed with any of our services, which you did and did not raise any concerns.

After you called us on the 31st of January, our site manager and team member visited your location to inspect your car.

Upon inspection, we were convinced that this damage was not due to our steam and if it had been caused by our team members, our manager and yourself who were both present at the wash, would have noticed it.

We pride ourselves in serving our customers and that is why we came to inspect your car as you requested.

We appreciate and value your feedback and always look to improve our services.

Thank you.

Zohaib Hassan Well that's not the complete story. They ruined my meter screen from Steam and they accept it. By high pressure steam they tore the roof cloth and were confused what to say, whether to accept it or not. My car roof lights were filled water steam water and it ruined the door lightning system. To fix all that I spent another Rs. 18640/- at dealer.

Like · Reply - 1y

Zohaib Hassan One more thing I never inspected my car after your so called detailing, as it was completely dark and even they didn't clean single glass of my car and even they were hell filled with steam all over and can't see anything inside the car. For your another lie of timings. When your guy called me @ 4.00 PM that we are on our way and will reach you in another 30 mins I confirmed it and waited till 5.30 PM and called them myself to confirm, no body from your side informed me anything about stuck in rush or some fool excuse. If you guys can't get your job dine like professionals don't act like one.

Like · Reply - 1y 


\section{REFERENCES}

Ali, R., \& Shams, Z. I. (2015). Quantities and composition of shore debris along Clifton Beach, Karachi, Pakistan. Journal of coastal conservation, 19(4), 527-535

Chen, P., Kang, S., Gul, C., Tripathee, L., Wang, X., Hu, Z., \& Pu, T. (2020). Seasonality of carbonaceous aerosol composition and light absorption properties in Karachi, Pakistan. Journal of environmental sciences, 90, 286-296.

Dholakia, U. M., Singh, S. S., \& Westbrook, R. A. (2010). Understanding the effects of post-service experience surveys on delay and acceleration of customer purchasing behavior: Evidence from the automotive services industry. Journal of Service Research, 13(4), 362-378.

Ghaly, A. E., Mahmoud, N. S., Ibrahim, M. M., Mostafa, E. A., \& Abdelrahman, E. N. (2021). Water Use, Wastewater Characteristics, Best Management Practices, and Reclaimed Water Criteria in the Carwash Industry: A Review. International Journal of Bioprocess and Biotechnological Advancements, 7(1), 240-261.

Mukaddas, M., Abdumurod, A., \& Otabek, A. (2021). Anticorrosive treatment as a means of car protection. Universum: технические науки, 4-5 (85), 37-40.

Sañudo-Fontaneda, L. A., Charlesworth, S. M., Castro-Fresno, D., Andres-Valeri, V. C., \& RodriguezHernandez, J. (2014). Water quality and quantity assessment of pervious pavements performance in experimental car park areas. Water Science and Technology, 69(7), 1526-1533.

Tabassum, R., Arsalan, M. H., Mumtaz, F., \& Imam, N. (2020). Sustainable urban water conservation strategy for a planned city of a developing country: a perspective from DHA City Karachi. Arabian Journal of Geosciences, 13(22), 1-11.

Zaneti, R. N., Etchepare, R., \& Rubio, J. (2013). Car wash wastewater treatment and water reuse-A case study. Water Science and Technology, 67(1), 82-88. 